John Carroll University

Carroll Collected

2018

Apps and Autonomy: Perceived Interactivity and Autonomous Regulation in mHealth Applications

Saraswathi Bellur

Christina DeVoss

Follow this and additional works at: https://collected.jcu.edu/fac_bib_2018

Part of the Communication Technology and New Media Commons, and the Social Media Commons 


\section{Apps and Autonomy: Perceived Interactivity and Autonomous Regulation in mHealth Applications}

Thousands of smartphone apps geared toward monitoring health behaviors are released regularly. Even as developers flood the market with mHealth apps, consumers seem overwhelmed with choices and report lack of sustained use, which raises questions about their efficacy. An online survey $(\mathrm{N}=513)$ found that perceived interactivity not only has a direct effect but also exerts an indirect effect via greater autonomous regulation on users' attitudes and behavioral intentions toward mHealth apps. Frequency of tracking and updating personal data showed significant effects on behavioral intentions. Theoretical and practical suggestions for the design and evaluation of mHealth apps are discussed.

Keywords: Autonomy; E/M-Health; Interactivity; mHealth Apps; Self-Monitoring

Investments in the mobile health applications (mHealth apps) market are growing, with the wearables market estimated to be about $\$ 19$ billion by 2018 (PharmaVoice, 2018). Globally, nearly 133 million units of wearables were sold, with fitness and health tracking apps being the most popular among millennials (Beaver, 2018). With nearly 325,000 health apps already available (Research2Guidance, 2017) and more being developed, it is important to understand if and how these apps are effective. In 2015 , less than a quarter (24\%) of health apps surpassed a 50,000-downloads mark (Berthene, 2016). Associated with these low downloads, other reports suggest lack of long-term engagement, suggesting that the sheer availability of apps does not always 
result in actual use. Research attributes this to a lack of understanding of theory and motivational techniques in the design of these apps (Conroy, Yang, \& Maher, 2014; Shute, 2014). For instance, the motivational technology model (Sundar, Bellur, \& Jia, 2012) proposes that technological affordances, such as interactivity, can positively influence individuals' intrinsic motivation and subsequently promote better health attitudes and behavior. The extant research on interactivity has focused mainly on Web-based platforms (Yang \& Shen, 2018), with limited studies in mobile contexts (Gao, Rau, \& Salvendy, 2010). Thus, we examine whether perceptions of interactivity in mHealth apps affect users' motivation, attitudes, and intentions.

\section{Interactivity and Perceived Interactivity}

Interactivity has been a widely studied concept. While some scholars have argued that interactivity is a technological attribute, calling it "actual" or objective interactivity (Liu \& Shrum, 2002; McMillan, 2002; Sundar, 2004, 2007; Williams, Rice, \& Rogers, 1988), others have recognized the importance of subjective evaluations, also called perceived interactivity (Bucy, 2004; Bucy \& Tao, 2007; Liu \& Shrum, 2002; Wu, 2005). Several studies have shown that the mere presence (or addition) of actual interactivity does not guarantee correspondingly higher perceptions (i.e., greater subjective evaluations) of interactivity in the minds of users (Bucy \& Tao, 2007; Chu \& Yuan, 2013; Song \& Zinkhan, 2008; van Noort, Voorveld, \& van Reijmersdal, 2012; Voorveld, Neijens, \& Smit, 2011). Further, a recent meta-analysis (Yang \& Shen, 2018) showed that the effect sizes of perceived interactivity tend to be much larger than that of objective interactivity.

In the realm of health technologies, McMillan (2002) found that a perception-based model was a better predictor of attitudes and relevance than a feature-based one. Perceived interactivity mediated the effects of regulatory fit on brand satisfaction (Jin \& Lee, 2010) and led to greater user satisfaction and repeat use (Willoughby \& L'Engle, 2015). Gustafson et al. (2014) found that users of an interactive app designed to offer continuing care for alcohol use disorders reported fewer risky drinking days due to enhanced patient-counselor interaction via the app. Lu, Kim, Dou, and Kumar (2014) reported greater behavioral intentions (visiting and recommending a fitness center) due to heightened interactivity and media richness. Hence, prior empirical research shows that interactivity can influence users' attitudinal and behavioral outcomes, leading to the following hypothesis:

H1: Greater perceived interactivity will lead to more positive attitudes (H1a) and behavioral intentions (H1b) toward mHealth apps.

\section{Self-Monitoring, Self-Determination, and Interactivity}

Trying to learn more about daily behaviors, our patterns, and ourselves is an innate human drive (Fogg, 2003). Hence, interactive technologies that tap into this drive for constant self-monitoring (e.g., keeping track of calories consumed, steps taken, heart 
rate, etc.) are said to enhance perceptions of autonomy (Sundar et al., 2012). An advantage offered by mHealth applications is that they encourage constant selfmonitoring or tracking of personal data (Consolvo, McDonald, \& Landay, 2009; Heffernan et al., 2016). Autonomy is also a central construct in self-determination theory (SDT), which distinguishes between autonomous and controlled regulation of individual behavior (Deci \& Ryan, 2000). Behaviors that are autonomy driven are said to be inherently rewarding, allowing for maximum personal growth and development. In contrast, behaviors that are determined by external factors (e.g., doctor's recommendations) are not self-driven. Hence, controlled regulation motives are likely to be inversely related to self-monitoring and autonomy-enhancing activities afforded by interactive interfaces (Dennison, Morrison, Conway, \& Yardley, 2013; Heffernan et al., 2016). Given interactivity's potential to boost autonomy (Fogg, 2003; Sundar et al., 2012), we believe that greater perceived interactivity will be positively associated with autonomous regulation and negatively related to controlled regulation. Several studies on chronic illness and disease management have provided empirical support for the effectiveness of self-regulation in meeting health goals (Maes \& Karoly, 2005). However, we do not know if these findings extend to newer forms of health regulation via mobile apps; thus, we examine how users' evaluations of interactivity in mHealth apps contribute toward autonomous and controlled regulation:

H2: Greater perceived interactivity in mHealth apps will be positively associated with autonomous regulation ( $\mathrm{H} 2 \mathrm{a})$ and negatively associated with controlled regulation $(\mathrm{H} 2 \mathrm{~b})$ motives.

The motivational technology model (Sundar et al., 2012) proposes that effects of interactivity on preventive health attitudes and behaviors are mediated by one's intrinsic motivation. Based on this, we explore whether perceived interactivity has an indirect effect on attitudes and intentions via more autonomous (i.e., more intrinsic) versus controlled regulation:

RQ1: Does autonomous regulation positively mediate the effects of perceived interactivity on attitudes (RQ1a) and behavioral intentions (RQ1b) toward mHealth apps?

RQ2: Does controlled regulation negatively mediate the effects of perceived interactivity on attitudes (RQ2a) and behavioral intentions (RQ2b) toward mHealth apps?

\section{Self-Monitoring Features in mHealth Applications}

Even though automatic tracking of health information is one of the most desired features (Rabin \& Bock, 2011), very few mobile apps include one (Breton, Fuemmeler, \& Abroms, 2011). When a self-monitoring feature is present and used regularly, it encourages individuals to engage in desirable health behaviors (Klasnja \& Pratt, 2012) such as more intentional physical activity (Consolvo et al., 2008; Turner-McGrievy et al., 2013) and weight reduction (Mattila et al., 2008). When users deliberately monitor their everyday activities, these applications foster greater self-awareness and 
provide novel insights (Dennison et al., 2013). However, it is unclear what specific technological features of mHealth apps are integral to this self-monitoring process. Conceptually, this study looked at two types of self-monitoring: tracking (generalized monitoring of health behaviors via mobile apps) and updating (specific activities, such as editing and customizing personal health information). Self-monitoring is active and user driven. In contrast, automatic, sensor-based tracking is more passive, with minimal user involvement. Thus, we examine the effects of two unique features of self-monitoring in mobile media-tracking and updating personal health information:

RQ3: Does frequent tracking lead to more positive attitudes and behavioral intentions toward mHealth apps?

RQ4: Does frequent updating lead to more positive attitudes and behavioral intentions toward mHealth apps?

\section{Method}

\section{Participants}

We conducted an online survey on Amazon's Mechanical Turk (MTurk) platform. Participants had to be 18 years old or older, users of mHealth apps, and residents of the United States to participate. Participants received $\$ 1.00$ for participating. The sample consisted of 513 individuals ( $47.5 \%$ were female), and the mean age was 30.3 years $(S D=8.3)$.

\section{Measures}

\section{Perceived interactivity}

Users' perception of interactivity toward mHealth apps was measured via 12 items. The items were adapted from prior studies that tapped into various dimensions of interactivity, such as active control, responsiveness, two-way communication, etc. (Leiner \& Quiring, 2008; Liu, 2003; Liu \& Shrum, 2002; McMillan \& Hwang, 2002; $\mathrm{Wu}, 2005)$. An exploratory factor analysis (EFA) with principal axis factoring and oblique rotation was used to explore underlying factors among the observed variables, since it examines both common and unique variance (Park, Dailey, \& Lemus, 2002). The results of this analysis show a unidimensional factor for perceived interactivity, with one factor explaining $49.39 \%$ of the variance. The factor matrix showed two items with poor factor loadings (less than 0.5 ), which were excluded (Tabachnick \& Fidell, 2012). This resulted in a 10-item, unidimensional scale of perceived interactivity.

Autonomous and controlled regulations

Autonomous regulation (six items) examined the extent to which participants used mHealth apps for their intrinsic value and enjoyment. The controlled regulation (six 
items) tapped into extrinsic factors that drove mHealth apps use. These items were adapted from Ryan and Connell (1989).

\section{Attitude and behavioral intentions}

An overall attitude measure was created using a scale of 15 items, which assessed users' evaluations on how well a set of adjectives described mHealth apps. A behavioral intention measure (five items) captured users' intention to continue their engagement with mHealth applications. These measures were adapted from Sundar, Bellur, Oh, Xu, and Jia (2014).

\section{Self-monitoring measures}

Frequency of tracking was measured by asking participants how often they keep track of changes in their health using an app on a scale from 1 (never) to 5 (very frequently). Frequency of updating tapped into how often they update their information on apps, measured from 1 (several times a day) to 5 (once or twice a month), reverse coded. Users' perceived competence in using cell phones, prior app downloads, and demographics were used as covariates.

\section{Results}

Findings from multiple regression analyses (Table 1) indicated that perceived interactivity positively predicted attitudes (H1a: $\beta=.50, p<.001)$ and behavioral intentions ( $\mathrm{H} 1 \mathrm{~b}: \beta=.40, p<.001$ ). As proposed in $\mathrm{H} 2 \mathrm{a}$ and $\mathrm{H} 2 \mathrm{~b}$, perceived interactivity was positively correlated with autonomous regulation and negatively correlated with controlled regulation (Table 2).

Further, supplemental mediation analyses (Hayes, 2013, PROCESS model 4, with 5,000 bootstrap samples and 95\% confidence intervals) showed that autonomous regulation did lead to positive indirect effects, mediating the effect of perceived interactivity on attitudes $(a b=.05 ; \mathrm{LLCI}=.02$, ULCI $=.09)$ and behavioral intentions $(a b=.11 ;$ LLCI $=.06$, ULCI $=.16$; RQ1a and RQ1b). Given cross-sectional data, we tested an alternative mediation model and found that perceived interactivity mediated the effects of autonomous regulation on attitudes $(a b=.14$; LLCI $=.10$, ULCI $=.19)$ and behavioral intentions $(a b=.12$; LLCI $=.08$, ULCI $=.17)$.

Additionally, attitudes also significantly mediated the effects of perceived interactivity $(a b=.29 ; \mathrm{LLCI}=.22, \mathrm{UCLI}=.37)$, frequency of tracking $(a b=.06 ; \mathrm{LLCI}=.03, \mathrm{ULCI}=.10)$, and frequency of updating $(a b=.04$; LLCI $=.01$, UCLI $=.07)$ on behavioral intentions. Controlled regulation did not lead to any significant indirect effects (RQ2a and RQ2b). Frequency of tracking (RQ3: $\beta=.09, p=.04$ ) and frequency of updating (RQ4: $\beta=.09$, $p=.04$ ) had a positive influence on behavioral intentions but not on attitudes. 
Table 1 Linear Regression Models on Attitudes and Behavioral Intentions.

\begin{tabular}{lcccc}
\hline & $\beta$ & $B$ (Std. Error) & $t$ & sig. \\
\hline DV: Attitudes & & & & \\
Age & $.10^{*}$ & $.01(.00)$ & 2.75 & .01 \\
Gender & -.01 & $-.02(.05)$ & -.34 & .73 \\
Ethnicity & .07 & $.04(.02)$ & 1.88 & .06 \\
Education & $-.11^{\star *}$ & $-.11(.03)$ & -3.03 & .00 \\
Income & -.02 & $-.01(.02)$ & -.60 & .55 \\
Prior app download & $.13^{* *}$ & $.10(.03)$ & 3.22 & .00 \\
Cell phone competence & $.11^{\star}$ & $.13(.05)$ & 2.80 & .01 \\
Perceived interactivity & $.50^{* *}$ & $.54(.04)$ & 12.81 & .00 \\
Frequency of tracking & -.01 & $.00(.03)$ & -.15 & .88 \\
Frequency of updating & .05 & $.03(.02)$ & 1.30 & .19 \\
Adj. $R^{2}$ & .38 & & & \\
DV: Behavioral Intentions & & & & \\
Age & $.08^{*}$ & $.01(.00)$ & 2.02 & .04 \\
Gender & -.05 & $-.08(.06)$ & -1.39 & .17 \\
Ethnicity & -.01 & $-.01(.03)$ & -.38 & .71 \\
Education & .05 & $.05(.04)$ & 1.28 & .20 \\
Income & -.05 & $-.04(.03)$ & -1.28 & .20 \\
Prior app download & $.11^{*}$ & $.10(.04)$ & 2.63 & .01 \\
Cell phone competence & $.13^{* *}$ & $.18(.06)$ & 3.10 & .00 \\
Perceived interactivity & $.40^{* *}$ & $.49(.05)$ & 9.64 & .00 \\
Frequency of tracking & $.09^{*}$ & $.07(.03)$ & 2.10 & .04 \\
Frequency of updating & $.09^{*}$ & $.05(.03)$ & 2.07 & .04 \\
Adj. $R^{2}$ & .33 & & & \\
\hline
\end{tabular}

Note. The VIF scores range from 1.05 to 1.50 , suggesting that multicollinearity is not an issue. ${ }^{\star} p<.05,{ }^{* *} p<.001$

\section{Discussion}

The key contributions from this study can be summarized as follows: (a) it is important to account for users' subjective experience of interactivity when evaluating mHealth apps; (b) apps that encourage greater autonomous regulation among users lead to favorable outcomes; and (c) designs of future mHealth apps need to be based on theoretical considerations of what features work and why.

Our findings are consistent with the literature on the importance of perceived interactivity, which significantly impacted both attitudes and behavioral intentions. This study not only replicates the positive effects of perceived interactivity, typically studied in Web-based domains (Yang \& Shen, 2018), but also extends it to mHealth apps. Further, the mediation analyses showed that perceived interactivity promoted a greater sense of autonomous regulation, which subsequently influenced attitudes and behavioral intentions. This is consistent with prior findings, which have shown that 


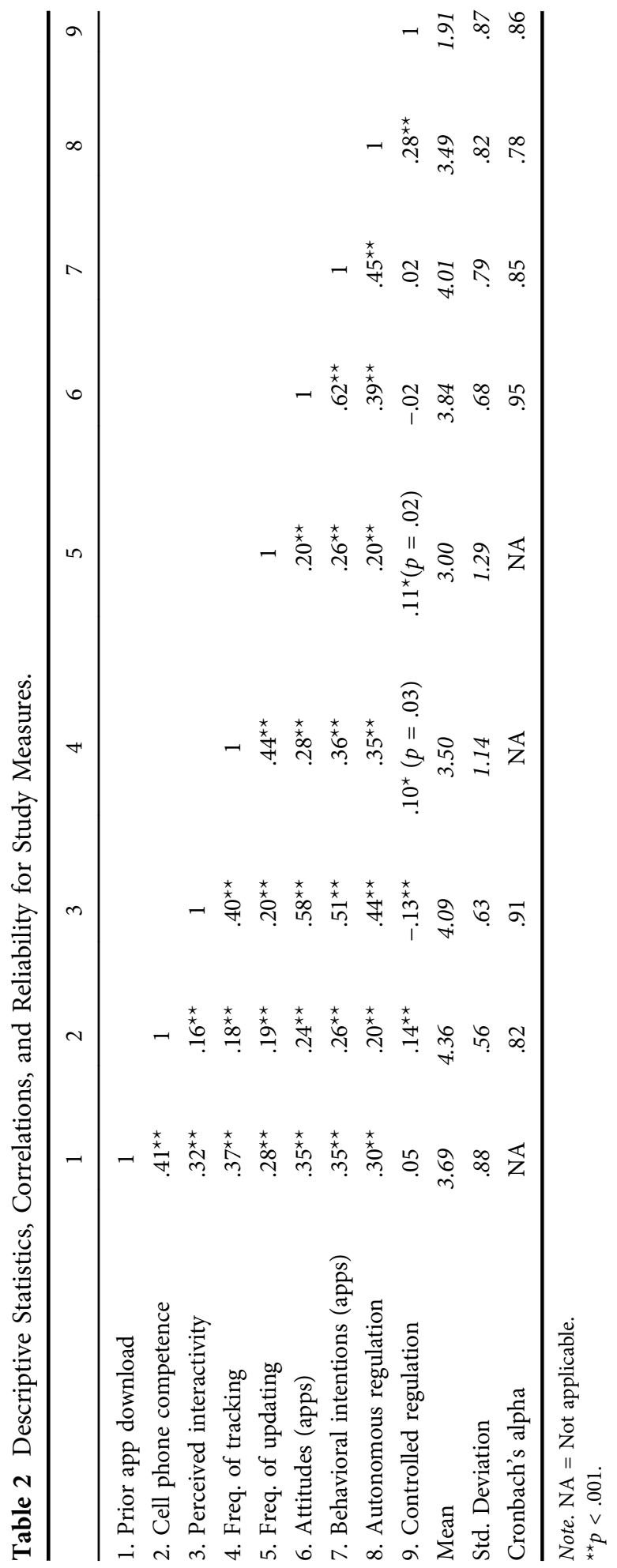


intuitive, user choice drives app-selection decisions (Dogruel, Joeckel, \& Bowman, 2015). Supplemental analyses also showed that attitudes significantly mediated the effects of perceived interactivity, tracking, and updating on behavioral intentions. This could be understood via the theory of planned behavior (Ajzen, 1991), which posits attitudes as an important antecedent to behavior. Tests of these theoretically driven variables and paths add more nuance to our understanding of mHealth apps.

The two self-monitoring features explored in this study (frequency of tracking and updating) positively predicted behavioral intentions and were also positively correlated with autonomous regulation. Based on these results, creating incentives for frequent "check-ins" via text notifications, reward points, and building other active user engagement metrics into these apps are some recommendations to app designers. Several users rely on automatic updates, which are convenient. Nevertheless, our findings indicate that those who report frequently (more actively) monitoring their everyday health activities show greater autonomous regulation, which in turn predicts greater attitudes and intentions. These self-monitoring features inform both future app design and research intervention (outcome measures) strategies.

With survey design, this study explored direct and indirect associations among variables. Future research should investigate causal mechanisms that can systematically rule out alternative explanations. Examining specific types of mHealth apps and experimentally varying the levels of self-monitoring and interactivity are fruitful areas for future research. We need studies comparing perceived interactivity in mobile-based versus Web-based platforms, with more items that tap into other factors (e.g., active control) of this multidimensional construct. While frequency of tracking and updating gave preliminary insight into users' behavioral intentions, we need additional measures that can capture the concept of self-monitoring more comprehensively. Beyond autonomy, future research should also explore the role of competence and relatedness on mHealth app evaluations.

\section{Disclosure statement}

No potential conflict of interest was reported by the authors.

\section{References}

Ajzen, I. (1991). The theory of planned behavior. Organizational Behavior and Human Decision Processes, 50(2), 179-211. doi:10.1016/0749-5978(91)90020-T

Beaver, L. (2018, May). Digital Health Briefing: Millennials are leading the consumerization of healthcare - Digital health will help drive wearable shipments - Paper records remain a data hazard for patients. Business Insider. Retrieved from http://www.businessinsider.com/digitalhealth-briefing-millennials-are-leading-the-consumerization-of-healthcare-digital-health-willhelp-drive-wearable-shipments-paper-records-remain-a-data-hazard-for-patients-2018-3 
Berthene, A. (2016, October 17). There are many more mobile health apps, but consumer interest flags. Internet Health Management. Retrieved from https://www.internethealthmanagement. com/2016/10/17/many-mobile-health-apps-consumer-interest-flags/

Breton, E. R., Fuemmeler, B. F., \& Abroms, L. C. (2011). Weight loss-There is an app for that! But does it adhere to evidence-informed practices? Translational Behavioral Medicine, 1, 523-529. doi:10.1007/s13142-011-0076-5

Bucy, E. P. (2004). Interactivity in society: Locating an elusive concept. The Information Society, 20, 373-383. doi:10.1080/01972240490508063

Bucy, E. P., \& Tao, -C.-C. (2007). The mediated moderation model of interactivity. Media Psychology, 9(3), 647-672. doi:10.1080/15213260701283269

Chu, K. M., \& Yuan, J. C. (2013). The effects of perceived interactivity on e-trust and e-consumer behaviors: The application of fuzzy linguistic scale. Journal of Electronic Commerce Research, 14, 124-136.

Conroy, D. E., Yang, C. H., \& Maher, J. P. (2014). Behavior change techniques in top-ranked mobile apps for physical activity. American Journal of Preventive Medicine, 46, 649-652. doi:10.1016/ j.amepre.2014.01.010

Consolvo, S., Klasnja, P., McDonald, D. W., Avrahami, D., Froehlich, J., LeGrand, L., ... Landay, J. A. (2008). Flowers or a robot army?: Encouraging awareness \& activity with personal, mobile displays. Proceedings of the 10th International Conference on Ubiquitous Computing - UbiComp '08 (pp. 54-63). New York, NY: ACM. doi:10.1145/1409635.1409644

Consolvo, S., McDonald, D. W., \& Landay, J. A. (2009). Theory-driven design strategies for technologies that support behavior change in everyday life. Proceedings of the 27th International Conference on Human Factors in Computing Systems CHI 09, CHI 2009 (6) (pp. 405414). New York, NY: ACM. doi:10.1145/1518701.1518766

Deci, E. L., \& Ryan, R. M. (2000). The "What" and "Why" of goal pursuits: Human needs and the self-determination of behavior. Psychological Inquiry, 11(4), 227-268. doi:10.1207/ S15327965PLI1104_01

Dennison, L., Morrison, L., Conway, G., \& Yardley, L. (2013). Opportunities and challenges for smartphone applications in supporting health behavior change: Qualitative study. Journal of Medical Internet Research, 15(4), e86. doi:10.2196/jmir.2583

Dogruel, L., Joeckel, S., \& Bowman, N. D. (2015). Choosing the right app: An exploratory perspective on heuristic decision processes for smartphone app selection. Mobile Media \& Communication, 3(1), 125-144. doi:10.1177/2050157914557509

Fogg, B. J. (2003). Persuasive technology: Using computers to change what we think an do. San Francisco, CA: Morgan Kaufmann Publishers.

Gao, Q., Rau, P.-L. P., \& Salvendy, G. (2010). Measuring perceived interactivity of mobile advertisements. Behaviour \& Information Technology, 29(1), 35-44. doi:10.1080/01449290802666770

Gustafson, D. H., McTavish, F. M., Chih, M.-Y., Atwood, A. K., Johnson, R. A., Boyle, M. G., ... Shah, D. (2014). A smartphone application to support recovery from alcoholism. JAMA Psychiatry, 71, 566-572. doi:10.1001/jamapsychiatry.2013.4642

Hayes, A. F. (2013). Introduction to mediation, moderation, and conditional process analysis: A regression-based approach. New York, NY: The Guilford Press.

Heffernan, K. J., Chang, S., Maclean, S. T., Callegari, E. T., Garland, S. M., Reavley, N. J., ... Wark, J. D. (2016). Guidelines and recommendations for developing interactive eHealth apps for complex messaging in health promotion. JMIR mHealth and uHealth, 4, e14. doi:10.2196/ mhealth.4423

Jin, S. A. A., \& Lee, K. M. (2010). The influence of regulatory fit and interactivity on brand satisfaction and trust in e-health marketing inside 3D virtual worlds (Second Life). Cyberpsychology, Behavior, and Social Networking, 13, 673-680. doi:10.1089/cyber.2009.0292

Klasnja, P., \& Pratt, W. (2012). Healthcare in the pocket: Mapping the space of mobile-phone health interventions. Journal of Biomedical Informatics, 45, 184-198. doi:10.1016/j.jbi.2011.08.017 
Leiner, D. J., \& Quiring, O. (2008). What interactivity means to the user: Essential insights into and a scale for perceived interactivity. Journal of Computer-Mediated Communication, 14(1), 127155. doi:10.1111/j.1083-6101.2008.01434.x

Liu, Y. (2003). Developing a scale to measure the interactivity of websites. Journal of Advertising Research, 43(2), 207-216. doi:10.1017/S0021849903030204

Liu, Y., \& Shrum, L. J. (2002). A dual-process model of interactivity effects. Journal of Advertising, 38 (2), 53-68. doi:10.2753/JOA0091-3367380204

Lu, Y., Kim, Y., Dou, X., (Yuki), \& Kumar, S. (2014). Promote physical activity among college students: Using media richness and interactivity in web design. Computers in Human Behavior, 41, 40-50. doi:10.1016/j.chb.2014.08.012

Maes, S., \& Karoly, P. (2005). Self-regulation assessment and intervention in physical health and illness: A review. Applied Psychology: An International Review, 54, 267-299. doi:10.1111/ j.1464-0597.2005.00210.x

Mattila, E., Parkka, J., Hermersdorf, M., Kaasinen, J., Vainio, J., Samposalo, K., ... Korhonen, I. (2008). Mobile diary for wellness management-Results on usage and usability in two user studies. IEEE Transactions on Information Technology in Biomedicine, 12, 501-512. doi:10.1109/TITB.2007.908237

McMillan, S. J. (2002). A four-part model of cyber-interactivity: Some cyber-places are more interactive than others. New Media \& Society, 4, 271-291. doi:10.1177/146144480200400208

McMillan, S. J., \& Hwang, J. S. (2002). Measures of perceived interactivity: An exploration of the role of direction, user control, and time in shaping perceptions of interactivity. Journal of Advertising, 31(3), 29-42. doi:10.1080/00913367.2002.10673674

Park, H. S., Dailey, R., \& Lemus, D. (2002). The use of exploratory factor analysis and principal components analysis in communication research. Human Communication Research, 28(4), 562-577. doi:10.1111/hcre.2002.28.issue-4

PharmaVoice. (2018). Showcase: MHealth: The power of mHealth in transforming health delivery. Retrieved from http://www.pharmavoice.com/article/2018-05-health-delivery/

Rabin, C., \& Bock, B. (2011). Desired features of smartphone applications promoting physical activity. Telemedicine and e-Health, 17(10), 801-803. doi:10.1089/tmj.2011.0055

Research2Guidance. (2017). mHealth App Economics 2017: Current status and future trends in mobile health. Retrieved from https://research2guidance.com/product/mhealth-economics2017-current-status-and-future-trends-in-mobile-health/

Ryan, R. M., \& Connell, J. P. (1989). Perceived locus of causality and internalization: Examining reasons for acting in two domains. Journal of Personality and Social Psychology, 57(5), 749761. doi:10.1037/0022-3514.57.5.749

Shute, N. (2014, May 6). Most fitness apps don't use proven motivational techniques. National Public Radio. Retrieved from http://tinyurl.com/hj8a5am

Song, J. H., \& Zinkhan, G. M. (2008). Determinants of perceived web site interactivity. Journal of Marketing, 72, 99-113. doi:10.1509/jmkg.72.2.99

Sundar, S. S. (2004). Theorizing interactivity's effects. The Information Society, 20, 385-389. doi:10.1080/01972240490508072

Sundar, S. S. (2007). Social psychology of interactivity in human-website interaction. In A. N. Joinson, K. Y. A. McKenna, T. Postmes, \& U.-D. Reips (Eds.), The Oxford handbook of internet psychology (pp. 89-104). Oxford, UK: Oxford University Press.

Sundar, S. S., Bellur, S., \& Jia, H. (2012). Motivational technologies: A theoretical framework for designing preventive health applications. In M. Bang \& E. L. Ragnemalm (Eds.), Proceedings of the 7th International Conference on Persuasive Technology (PERSUASIVE 2012), LNCS 7284 (pp. 112-122). doi:10.1007/978-3-642-31037-9_10

Sundar, S. S., Bellur, S., Oh, J., Xu, Q., \& Jia, H. (2014). User experience of on-screen interaction techniques: An experimental investigation of clicking, sliding, zooming, hovering, dragging and flipping. Human Computer Interaction, 29(2), 109-152. doi:10.1080/07370024.2013.789347 
Tabachnick, B. G., \& Fidell, L. S. (2012). Using multivariate statistics (6th ed.). Needham Height, MA: Allyn \& Bacon.

Turner-McGrievy, G. M., Beets, M. W., Moore, J. B., Kaczynski, A. T., Barr-Anderson, D. J., \& Tate, D. F. (2013). Comparison of traditional versus mobile app self-monitoring of physical activity and dietary intake among overweight adults participating in an mHealth weight loss program. Journal of the American Medical Informatics Association, 20, 513-518. doi:10.1136/amiajnl2012-001510

van Noort, G., Voorveld, H. A., \& van Reijmersdal, E. A. (2012). Interactivity in brand web sites: Cognitive, affective, and behavioral responses explained by consumers' online flow experience. Journal of Interactive Marketing, 26, 223-234. doi:10.1016/j.intmar.2011.11.002

Voorveld, H. A. M., Neijens, P. C., \& Smit, E. G. (2011). The relation between actual and perceived interactivity. Journal of Advertising, 40, 77-92. doi:10.2753/JOA0091-3367400206

Williams, F., Rice, R. E., \& Rogers, E. M. (1988). Research methods and the new media. New York, NY: The Free Press.

Willoughby, J. F., \& L'Engle, K. L. (2015). Influence of perceived interactivity of a sexual health text message service on young people's attitudes, satisfaction and repeat use. Health Education Research, 30(6), 996-1003. doi:10.1093/her/cyv056

$\mathrm{Wu}, \mathrm{G}$. (2005). The mediating role of perceived interactivity in the effect of actual interactivity on attitude toward the website. Journal of Interactive Advertising, 5(2), 29-39. doi:10.1111/ j.1559-1816.1998.tb01708.x

Yang, F., \& Shen, F. (2018). Effects of web interactivity. Communication Research, 45(5), 635-658. doi:10.1177/0093650217700748 